\title{
LOW SEVERITY CONVERSION OF ACTIVATED COAL
}

\author{
Final Report
}

By

Albert S. Hirschon

David S. Ross

January 1990

Work Performed Under Contract No. DE-FG22-87PC79936

For

U.S. Department of Energy

Pittsburgh Energy Technology Center

Pittsburgh, Pennsylvania

By

SRI International

Menlo Park, California 


\section{SUMMARY}

This final report summarizes our research on Contract No. DE-FG22-87PC79936, "Low Severity Conversion of Activiated Coal." The objectives of this project were to (1) develop an understanding of hydrothermal pretreatment chemistry and its optimization at temperatures and pressures no greater than $250^{\circ} \mathrm{C}$ and $1000 \mathrm{psi}$, (2) develop a series of highly reactive and dispersible promoters of bond hydrogenolysis operating at temperatures no greater than $300^{\circ} \mathrm{C}$, and (3) successfully combine the pretreatment and hydrotreating steps to obtain high yields of toluenesoluble coal products. The program was divided into four tasks, the first of which was the development of a project work plan. Summaries of work in the three experimental tasks are described below. In addition, we have included several manuscripts in Appendices A through D.

\section{TASK 2: AQUEOUS PRETREATMENT}

Past work at SRI demonstrated a considerable improvement in yield when hydrothermally treated samples of a somewhat weathered lllinois No. 6 coal (PSOC $1098 ; 250^{\circ} \mathrm{C} / 30 \mathrm{~min} / \mathrm{liquid}$ water) were liquefied in a basic $\mathrm{CO} / \mathrm{H}_{2} \mathrm{O}$ system. These results were confirmed in work on this program for the weathered coal, but later work on an Argonne Illinois No. 6 coal showed no such enhancement. Thus the difference was in some manner due to the weathering, an effect that should be looked into further.

The major focus of the work reported here was the effect of pretreatment on conventional H-donor conversions, and in this case there were no yield improvements with either the weathered or Argonne coals. Product quality, however, was substantially affected. Thus field ionization mass spectrometer (FIMS) studies of the toluene-soluble (TS) fractions from tetralin conversions showed that pretreatment of the starting coal lowered the temperature at half volatility from $250^{\circ} \mathrm{C}$ to $205^{\circ} \mathrm{C}$, while the number average molecular weight $\left(\bar{M}_{n}\right)$ of the TS fractions increased from 464 to 479 dalton. The product was thus at the same time more volatile and had a greater molecular weight. A breakdown of the $\bar{M}_{n}$ values showed the increase to be in the more volatile half of the product. Consistent with this result, the glass transition temperatures for the products of the tetralin co iversions of the as-received and pretreated coals varied from $+30^{\circ} \mathrm{C}$ and $-20^{\circ} \mathrm{C}$, respectively.

To understand the origins of the changes, we examined the pretreated coal itself. SEM (scanning electron microscope) analyses showed that the mineral phase of the coal was highly 
disrupted by the treatment. FIMS studies of the thermally evolved tars from both as-received and pretreated Illinois No. 6 coal by showed that the starting coal began to degrade at about $350^{\circ} \mathrm{C}$. In the case of the pretreated samples, however, simple arenes begin to evolve in the range $150^{\circ}$. $250^{\circ} \mathrm{C}$. These compounds are not wholly freed from the coal; rather, the components yielding them in pyrolysis were altered so that they were developed at considerably lower temperatures. This behavior is similar to that seen with oil shale in studies of accelerated maturation and suggests that the coal contains immature regions that evolve hydrocarbons at hydrothermal conditions. We further suspected that the favorable effects of hydrothermal pretreatment are linked to moderation of the regressive reactions in the later conversions.

\section{TASK 3. SYNTHESIS OF CLUSTERS AND REACTIVITY WITH MODEL SYSTEMS}

In this task, we prepared oil-soluble and water-soluble organometallic clusters. Our efforts were focused on developing soluble, highly reactive, metal cluster promoters for the hydrogenolysis of the heteroatom linkages and phenolic $\mathrm{C}-\mathrm{O}$ bonds in coal. These soluble catalysts were used in Task 4 to impregnate the coal structure with the goal of removing the heteroatoms and increasing yields and quality of the liquefied product. Ammonium thiomolybdate was used as the aqueous precursor, and cyclopentadiene molybdenum thiolate as the oil-soluble precursor. Cobalt complexes were reacted with each of the molybdenum complexes to form the respective cobalt molybdenum clusters. $\mathrm{Fe}(\mathrm{CO})_{5}$ and $\mathrm{Fe}_{2} \mathrm{~S}_{2}(\mathrm{CO})_{6}$ were also used as catalysts for cnal conversions. Some of this work is presented in Appendices $\mathrm{C}$ and D.

\section{TASK 4: CATALYTIC CONVERSION OF COAL}

The goal of Task 4 was to link the pretreatment step from Task 2 with the dispersed highactivity hydrogenolysis catalysts synthesized in Task 3 , thus maximizing the conversion of coal to soluble products and minimizing any retrogressive reactions. To test these catalysts, we looked at low temperature hydrogenations $\left(300^{\circ} \mathrm{C}\right)$ and higher temperature conversions $\left(400^{\circ}-425^{\circ} \mathrm{C}\right)$ of the weathered Illinois No. 6 coal (PSOC 1098). For conversions of the unpretreated coal in $\mathrm{CO} / \mathrm{H}_{2} \mathrm{O}$, we found that the $\left(\mathrm{NH}_{4}\right)_{2} \mathrm{MoO}_{4}$ was ineffective but that $\left(\mathrm{NH}_{4}\right)_{2} \mathrm{MoS}_{4}$ resulted in high conversions. In all cases, the extent of conversion corresponded to the extent of water-gas-shift activity, and no pretreatment effects were observed. Similarly, no pretreatment benefit was observed in the nonaqueous conversions, using tetralin at $400^{\circ} \mathrm{C}$.

We compared several methods of impregnating an aqueous molybdenum catalyst into coal for subsequent tetralin conversions. The greatest yields for these aqueous impregnations were 
found to be when the coal was impregnated with the molybdenum and remained wet before conversion. When a nonaqueous impregnation technique with an organometallic molybdenum cluster was used, a still greater conversion to toluene-soluble material was achieved. Other organometallic complexes were examined to expand the scope of reactivity. A molybdenum tetraacetate complex gave an intermediate conversion between that of the aqueous method and that of a molybdenum sulfido complex. Conversion with an organometallic CoMo cluster gave the best yield. We also compared conversions using $\mathrm{Fe}(\mathrm{CO})_{5}$ and $\mathrm{Fe}_{2} \mathrm{~S}_{2}(\mathrm{CO})_{6}$ clusters and found that the sulfided iron complex appears to be slightly more active than $\mathrm{Fe}(\mathrm{CO})_{5}$ in conversions, but much less active than the organometallic molybdenum complexes. Appendix D contains a further description of these results. 


\section{CONTENTS}

\section{SUMMARY}

\section{INTRODUCTION.}

TASK 2: AQUEOUS PRETREATMENT..................................... 3

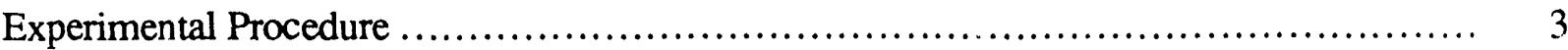

Liquefaction Experiments .............................................. 3

Analyses.................................................................. 3

Results........................................................................ 4

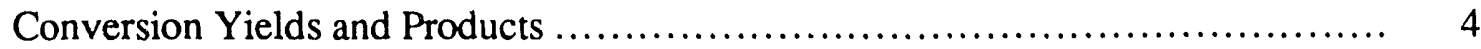

Pretreated Coal............................................................... 7

TASK 3: SYNTHESIS OF CLUSTERS AND REACTIVITY WITH

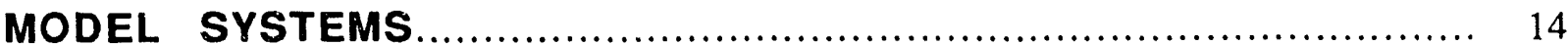

TASK 4: CATALYTIC CONVERSION OF COAL ......................... 16

Experimental Procedures .................................................... 16

Results.................................................................... 17

Low Temperature Hydrogenations........................................... 17

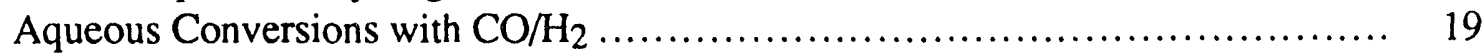

Nonaqueous Conversions............................................... 19

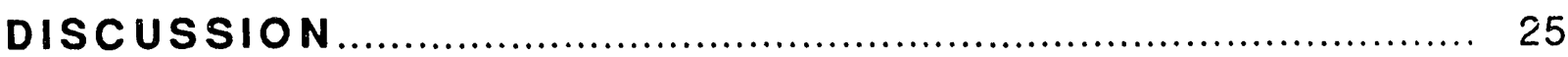

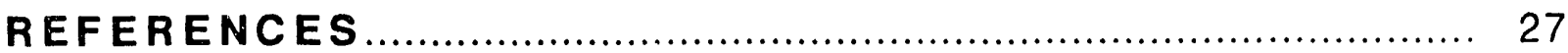

APPENDICES - Conf. papens eycled sepunalely
A COAL STRUCTURE AND BEHAVIOUR-INTERFACIAL CHEMISTRY IN COAL
B WEAK LINKS AND INTERFACIAL CHEMISTRY IN COAL
C USE OF PROMOTERS TO ENHANCE HYDRODENITROGENATION AND HYDRODEOXYGENATION CATALYSIS
D USE OF DISPERSED CATALYSTS FOR COAL LIQUEFACTION 


\section{INTRODUCTION}

Conventional coal liquefaction operates in a "brute force" mode, with conditions in the first, or thermal, step bringing about both indiscriminate bond breaking and bond generation. In the second (hydrotreating) step, the heteroatoms are removed catalytically, but at conditions so severe that excessive hydrogenation occurs. ${ }^{1}$

We have made advances at SRI in both the thermal and hydrotreating stages that can be applied to develop a more rational coal liquefaction scheme. The essence of our approach to liquefaction is to (1) increase both the reactivity and accessibility of coal by pretreatment and (2) use the bond-breaking capacity of reactive catalysts well dispersed within the coal structure. With this approach, we can expect moreover to minimize or eliminate the bond-generating or retrogressive reactions working at cross purposes to coal liquefaction.

The rationale for the pretreatment comes from our previous work on DOE contract DEFG22-83PC60778 and from recent accounts in the literature. In our work we found that brief pretreatment of an Illinois No. 6 coal with water at $240^{\circ} \mathrm{C}$ activated the coal to provide enhanced yields of toluene-soluble products on conversion. We also found that the activation was most pronounced when the coal was protected from air after pretreatment and before the final conversion step. The decrease in effect on exposure to air suggested that the pretreatment exposed or in some other manner generated reactive sites sensitive to oxygen.

Relevant published work includes that of Bienkowski et al., who found that water vapor/ammonia pretreatment enhanced liquefaction, ${ }^{2 \mathrm{a}}$ and Brandes and Graff, who reported that treatment of a bituminous coal treated in water vapor at $320^{\circ}-360^{\circ} \mathrm{C}$ increased the yields of condensibles in subsequent mild pyrolysis. ${ }^{2 b, c}$ They further found that the coal swelled to nearly twice its original volume with the pretreatment. Very recent pyrolysis work reported by Kahn et al. $2 \mathrm{~d}$ showed that pretreatment with water vapor at $300^{\circ}-320^{\circ} \mathrm{C}$ reduced the total oxygen content of low rank coals, but not of high rank coals. Phenols were released during the process, and the benefits of the pretreatment to pyrolytic production of condensibles were viewed as marginal.

The catalysis component of the approach evolves from recent work on DOE contract DEFG22-85PC80906, "Catalytic Methods for Improved Coal Liquefaction and Hydrotreating," in which we developed techniques for preparing novel, high-activity heterogeneous catalysts. These materials are exceptionally active in hydrogenolysis reactions at low temperatures, while 
minimizing hydrogen consumption. ${ }^{3-5}$ The techniques included the preparation of organometallic clusters to operate as multimetallic catalysts on the moiecular level. By impregnating these clusters on supports, we prepared catalysts for which each metal cluster contained the minimum number of metal atoms required for activity.

The program conducted on this contract was composed of four tasks. Task 1 was the preparation of the project work plan. Task 2 was a systematic study of compositional and morphological changes brought about by hydrothermal pretreatment, with the goal of developing an understanding of the pretreatment effect mechanism.

Task 3 consisted of the preparation of soluble organometallic clusters. Guided by our earlier work, efforts were made to develop soluble, highly reactive, metal cluster promoters for the hydrogenolysis of the heteroatom linkages and phenolic $\mathrm{C}-\mathrm{O}$ bonds in coal. The work involved a detailed survey using a series of model materials.

In Task 4 we linked the pretreatment step from Task 2 with dispersed high-activity hydrogenolysis catalysts synthesized in Task 3 , thus maximizing the conversion of coal to soluble products and minimizing any retrogressive reactions. 


\section{TASK 2: AQUEOUS PRETREATMENT}

\section{EXPERIMENTAL PROCEDURE}

\section{Liquefaction Experiments}

For the experiments involving pretreatment, the coal was pretreated by placing approximately $5 \mathrm{~g}$ of coal and $10 \mathrm{~mL}$ of distilled water in a $45-\mathrm{mL}$ Parr bomb with a Teflon insert. The reactor was purged and pressurized with $500 \mathrm{psi}$ of nitrogen and inserted into a preheated furnace for $30 \mathrm{~min}$ at $250^{\circ} \mathrm{C}$. After the reactor had cooled, the insert was removed and transferred into a centrifuge tube fitted with a screw cap. The aqueous layer was removed after centrifuging the mixture, and the pretreated coal was washed twice with distilled water (or $\mathrm{pH} 13 \mathrm{KOH}$ for the $\mathrm{CO} /$ water conversions). The treated coal was then mixed with $30 \mathrm{~g}$ of liquefaction medium and transferred to the $300-\mathrm{mL}$ Autoclave Engineers Magnedrive autoclave.

All operations were conducted either in a nitrogen-filled glove bag or under a blanket of nitrogen. The autoclave was then purged and pressurized with $500 \mathrm{psi}$ of either hydrogen or carbon monoxide and heated to $400^{\circ} \mathrm{C}$. The electric furnace could be raised or lowered by use of a remotely controlled jack. The typical heat-up time was $30 \mathrm{~min}$. After a 20 -min reaction, the furnace was immediately lowered, which gave a rapid cool down of about $100^{\circ} \mathrm{C}$ in about 5 minutes. After the reaction had cooled, the coal liquid and residue were taken up in tetrahydrofuran (THF). The THF was removed under reduced pressure and the residue taken up in toluene. The product was filtered through a medium porosity filter and separated into toluenesoluble (TS) and -insoluble (TI) fractions. The toluene and residual tetralin were then removed from the TS under reduced pressure. The TS and TI fractions were then dried at $76^{\circ} \mathrm{C}$ for $12 \mathrm{~h}$ under vacuum $(<0.1 \mathrm{~mm})$.

\section{Analyses}

Elemental analyses were performed by Galbraith Laboratories, Inc., in Knoxville, Tennessee.

The particle size distribution of the coal samples was determined on a Horiba particle size distribution analyzer, CAPA-700. 
For the field ionization mass spectrometry (FIMS) analysis, one gram of coal was heated in $10 \mathrm{~mL}$ of water at $250^{\circ} \mathrm{C}$ for the desired time. The water was removed by centrifuging the slurry as described above. The wet coal was dried under flowing nitrogen and transferred under nitrogen into a preweighed capillary capsule and placed into the FIMS pyrolysis chamber. The FIMS samples were heated in a high vacuum inlet assembly in intervals from ambient to $500^{\circ} \mathrm{C}$. The signal was recorded throughout the heating period.

\section{RESULTS}

\section{Conversion Yields and Products}

The work described here was conducted on two samples of Illinios No. 6 coal, a somewhat weathered coal (PSOC 1098), and an Argonne Premium coal. The focus of the study was conventional conversions in tetralin, but in some preliminary work, we looked into conversions in $\mathrm{CO} /$ water.

In the $\mathrm{CO} /$ water studies, we found that a 30 -min pretreatment provided considerable improventent in the convertibility (toluene solubility, TS) of the weathered coal, increasing the TS values from $35 \%$ for the as-received coal, to values greater than $70 \%$ as shown in Table 1 . In contrast, the convertibility of the Argonne coal was little affected. In other work with the weathered coal, the use of aqueous ammonia in the pretreatment had a modest effect, and exposure of the pretreated coal to the atmosphere appeared to lessen the benefit.

The differences between the effects on the weathered and Argonne coals are difficult to understand. It is notable that the TS fraction from the former has significantly greater quantities of oxygen, a factor that could reflect some feature of the specific chemistry leading to the benefit. Consistent with this view is the result for tetralin conversion, described below, where there is neither a pretreatment benefit nor increased oxygen in the TS fractions. In earlier work with unpretreated coal, we determined that the soluble products from $\mathrm{CO} /$ water and tetralin conversions were virtually identical. 6 The present results therefore suggest that weathering, i.e., oxidation, generates additional crosslinks that are then broken solely in $\mathrm{CO} /$ water conversions.

For the tetralin conversions, the yield results were somewhat different, as shown in Table 2. The pretreated material was only superficially dried to avoid the risk of altering the material through excessive drying, and some control runs therefore included conversions run with added water (referred to as "wet" tetralin runs below). Table 2 shows that there is little obvious change in the 
Table 1

\section{CO/WATER CONVERSIONS OF PRETREATED \\ ILLINOIS NO. 6 COALa}

\begin{tabular}{|c|c|c|c|c|}
\hline Run No. & Pretreatment & $\begin{array}{c}\text { Yield (mmf) } \\
w_{t} \%^{b}\end{array}$ & $\mathrm{H} / \mathrm{C}$ & $\mathrm{O} / \mathrm{C}^{\mathrm{c}}$ \\
\hline \multicolumn{5}{|l|}{ PSOC 1098} \\
\hline 1 & None & 35.6 & 1.07 & 0.05 \\
\hline 2 & & 35.4 & 1.02 & -- \\
\hline 3 & $3 \mathrm{M} \mathrm{NH}_{3}$ & 46.6 & 1.00 & 0.06 \\
\hline 4 & & 48.9 & 0.99 & 0.05 \\
\hline 5 & $\mathrm{H}_{2} \mathrm{O}$ & 69.0 & 1.13 & 0.09 \\
\hline 6 & & 73.4 & 1.13 & 0.12 \\
\hline 7 & $\mathrm{H}_{2} \mathrm{O} / \mathrm{aird}$ & 51.3 & 1.06 & -- \\
\hline \multicolumn{5}{|c|}{$\begin{array}{l}\text { Argonne Premium } \\
\text { samples }\end{array}$} \\
\hline 8 & None & 45.2 & -- & -- \\
\hline 9 & $\mathrm{H}_{2} \mathrm{O}$ & 46.9 & - & -- \\
\hline
\end{tabular}

a. Reaction in $300 \mathrm{~mL}$ autoclave of $5 \mathrm{~g}$ coal in $30 \mathrm{~mL}$ aqueous $\mathrm{KOH}$ at pH 13 and $500 \mathrm{psi} \mathrm{CO}$ at $400^{\circ} \mathrm{C}$ for 20 minutes. Coal $\left(5 \mathrm{~g}\right.$ ) was either pretreated with either $10 \mathrm{~mL} \mathrm{H}_{2} \mathrm{O}$ or $9 \mathrm{~mL}$ of $3 \mathrm{M} \mathrm{NH}_{3}(\mathrm{aq})$ at $250^{\circ} \mathrm{C}$ and $500 \mathrm{psi} \mathrm{N}_{2}$ in a $45-\mathrm{mL}$ Parr reactor.

b. Yield was calculated on mmf basis of toluene -soluble products.

c. Oxygen determined by difference.

d. Pretreated coal was exposed to laboratory air for $24 \mathrm{~h}$ before the conversion. 
Table 2

EFFECT OF PRETREATMENT ON CONVERSIONS OF ILLINOIS

NO. 6 COAL TO TOLUENE-SOLUBLE PRODUCTSa

\section{Pretreatment}

PSOC 1098
$\%$ TS (daf)

48

47

49

48

52

50

$\mathrm{H}_{2} \mathrm{O}(5 \mathrm{hr})$

49

Argonne Premium sample

None

59

$\mathrm{H}_{2} \mathrm{O}$ (30 min)

56

a Reaction conducted in $300-\mathrm{ml}$ autoclave with $5 \mathrm{~g}$ coal in $30 \mathrm{~g}$ tetralin and $500 \mathrm{psi} \mathrm{H}_{2}$ (cold) at $400^{\circ} \mathrm{C} / 20 \mathrm{~min}$ b Coal (5 g) was pretreated with $10 \mathrm{ml} \mathrm{H}_{2} \mathrm{O}$ at $250^{\circ} \mathrm{C}$ and $500 \mathrm{psi}_{2}$ (cold) in a $45 \mathrm{ml}$ Parr reactor.

$\mathrm{c}_{4} \mathrm{ml}$ water added to tetralin in the conversion. of as received coal.

\section{Table 3}

ELEMENTAL ANALYSES OF PRODUCTS FROM TETRALIN CONVERSIONS OF ILLINOIS NO. 6 COAL AT $400^{\circ} \mathrm{C} / 20 \mathrm{MIN}$

\begin{tabular}{|c|c|c|c|c|c|}
\hline Condition & Producta & $\mathrm{H} / \mathrm{C}$ & $\% 0$ (diff) & $\% \mathrm{~S}$ & $\% N$ \\
\hline Dry tetralin & $\begin{array}{l}\text { TS } \\
\text { TI }\end{array}$ & $\begin{array}{l}0.98 \\
0.77\end{array}$ & $\begin{array}{l}5.0 \\
--\end{array}$ & $\begin{array}{l}1.1 \\
--\end{array}$ & $\begin{array}{l}1.2 \\
1.9\end{array}$ \\
\hline Wet tetralin & $\begin{array}{l}\text { TS } \\
\text { TI }\end{array}$ & $\begin{array}{l}0.98 \\
0.81\end{array}$ & $\begin{array}{l}5.0 \\
--\end{array}$ & $\begin{array}{l}1.0 \\
-.\end{array}$ & $\begin{array}{l}1.4 \\
2.0\end{array}$ \\
\hline Pretreated & $\begin{array}{l}T S \\
T 1\end{array}$ & $\begin{array}{l}1.02 \\
0.73\end{array}$ & $\begin{array}{l}4.7 \\
--\end{array}$ & $\begin{array}{l}0.9 \\
--\end{array}$ & $\begin{array}{l}0.9 \\
2.0\end{array}$ \\
\hline
\end{tabular}

a. $\mathrm{TS}=$ toluene-soluble; $\mathrm{TI}=$ toluene-insoluble. 
conversions levels, and the elemental analyses presented in Table 3 show that there is no significant difference in the overall compositions of the TS fractions.

Nonetheless, we find the products from the donor conversions of the coal and pretreated coal to be significantly different. For example, there is a difference in physical appearance, with the coal yielding a brittle solid and the pretreated coal a tacky tar-like product. In accord with this difference, we found by differential scanning calorimetry that the glass transition temperatures are, respectively, around $-20^{\circ} \mathrm{C}$ and $+30^{\circ} \mathrm{C}$.

The differences are demonstrated more directly in the data presented in Figure 1, which compares the volatilities and number average molecular weights $\left(\overline{\mathrm{M}}_{n}\right)$ of the TS fractions from conversions of the pretreated and unpretreated material. The data were obtained with SRI's field ionization mass spectrometer (FIMS) in which the toluene-soluble fractions, fully volatile under these conditions, were evaporated into the instrument over temperatures from ambient to $500^{\circ} \mathrm{C}$ at a heating rate of $2.5^{\circ} \mathrm{C} / \mathrm{min}$. The data in Figure 1(a) show that the TS fraction from the pretreated coal is significantly more volatile than that from the untreated material. The temperatures at half volatility were $205^{\circ} \mathrm{C}$ and $250^{\circ} \mathrm{C}$ for the pretreated and unpretreated cases, respectively. The $\overline{\mathrm{M}}_{n}$ values of the products ranged monotonically from 150-200 amu for the most volatile portions to $750 \mathrm{amu}$ for the least volatile for both products, but with some prominent differences as shown in Figure 1(b). The figure shows a breakdown of $\bar{M}_{n}$ over temperature ntervals in terms of the difference $\bar{M}_{n}$ [pretreated] $-\bar{M}_{n}$ [wet tetralin], and substantial $\bar{M}_{n}$ differences are concentrated in the more volatile half. Thus $\Delta \overline{\mathrm{M}}_{n}$ grows to just above 100 amu up to about $200^{\circ} \mathrm{C}$, while the $\overline{\mathrm{M}}_{n}$ 's for the less volatile half of the products are similar.

\section{Pretreated Coal}

Elemental Analyses and Morphology. The changes described above suggested considerable differences in the pretreated coal; therefore, we conducted a series of comparisons between it and the as-received material. The elemental and ash analyses are presented in Figure 2; the $\mathrm{O}$-values were obtained by direct $\mathrm{O}$-analysis. The $\mathrm{H} / \mathrm{C}$ and $\mathrm{O} / \mathrm{C}$ ratios changed only slightly, but the bulk sulfur content was substantially reduced. The change in bulk sulfur was matched by lowered ash levels, the pretreatment affecting about $60 \%$ reductions in both cases. The similarity demonstrates that ash reduction by the hydrothermal medium must involve removal primarily of sulfur-containing material, most likely sulfate. These results are qualitatively similar to those of Rozgonyi et al., 7 who reported $39 \%$ and $31 \%$ reductions, respectively, in total sulfur and ash for a bituminous coal after hydrothermal treatment at $292^{\circ} \mathrm{C} / 40 \mathrm{~min}$. Our higher values may be due to our lower temperature, which minimizes thermal degradation of the organic portion of the coal. 


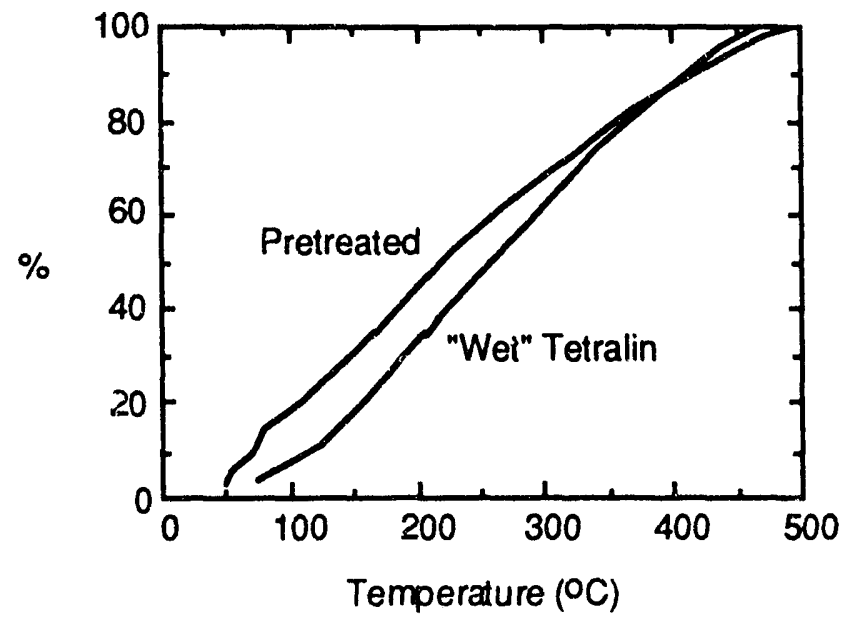

(a) Fraction of total volatility versus evaporation temperature.

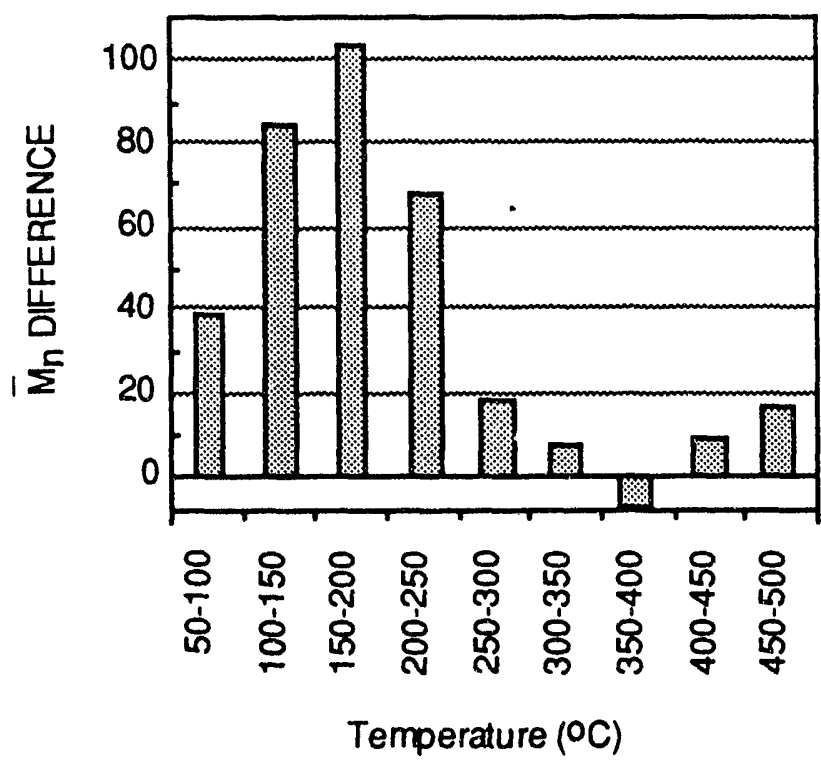

(b) Difference number average molecular weight (pretreated - wet tetralin) versus temperature.

RA-M-4275-14

Figure 1. Comparison of toluene-soluble fractions from conversions of pretreated and as-received coal 

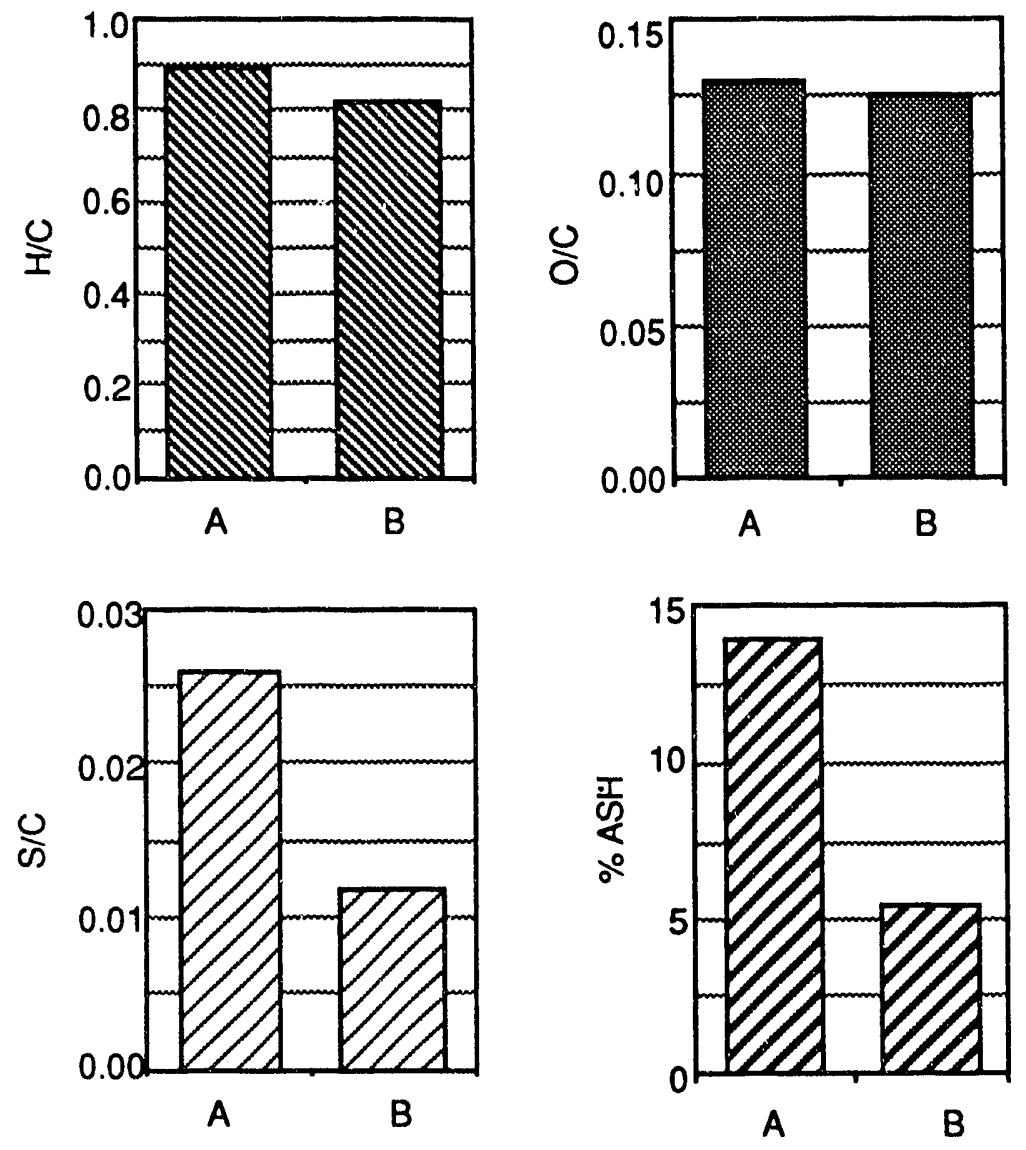
A. Untreated
B. 30 Min. Hydrothermal Pretreatment

RA-M-4275-15

Figure 2. Analytical data for untreated and hydrothermally pretreated Illinois No. 6 coal. 
Pyrite is essentially fully insoluble in water at these conditions, and these results are likely related to published accounts of how readily coal pyrite can be oxidized. It is reported, for example, that greater than $98 \%$ of the pyrytic sulfur in a fresh sample of Illinois No. 6 coal stored in an evacuated desiccator was oxidized to ferrous and ferric sulfate over a year. ${ }^{8}$ The material was exposed to the atmosphere for only short intervals over that period for sampling, and yet the mineral sulfur oxidation was virtually complete. We presume that our coal is similarly oxidized and that the resulting sulfate is therefore easily dissolved during the pretreatment step.

Geochemical studies of marine sediment maturation have shown that aqueous iron sulfate at hydrothermal conditions oxidizes organic material. ${ }^{9 a}$ This factor could play a key role in the pretreatment effect, since the sulfate in coal would be very finely dispersed. Indeed, in scanning electron microscope (SEM) and energy dispersive X-ray (EDX) studies, we found iron to be very broadly and evenly distributed throughout the organic phase of the coal. It could therefore be responsible for oxidatively breaking critical linking groups in the crosslinked matrix. Another explanation could be tied to the observation that, in the oxidation process, the sulfate is reduced to products containing pyrrhotite, $9 \mathrm{~b}$ and pyrrhotite has in turn been associated with the benefits to liquefaction produced by the $\mathrm{H}_{2} \mathrm{~S} / \mathrm{Fe}_{\mathrm{X}} \mathrm{S}$, family. ${ }^{9 \mathrm{c}}$ Thus oxidation of small quantities of organic material could result in relatively large quantities of very highly dispersed pyrrhotite, positively affecting the conversions.* This factor should be looked into in further study.

The SEM/EDX work showed the starting coal to be present in particles of nominally 50$200 \mu \mathrm{m}$, with separate particles representing both the bulk organic and bulk mineral phases. The hydrothermal treatment, however, substantially decreased the particle size of the coal, with the formation of a considerable fines fraction having nominal particle sizes below $1 \mu \mathrm{m}$. A profound change occurred in the bulk mineral phase, which became fragmented and irregular in appearance.

Just as for $\mathrm{Fe}$, considerable quantities of $\mathrm{Al}$ and $\mathrm{Si}$ were seen in the organic phase, an observation in line with the split of the mineral components in coal between the bulk organic and mineral phases discussed by Finkelman. ${ }^{10}$ Allen and VanderSande ${ }^{11}$ have estimated that mineral matter in the organic phase may represent up to $15 \%$ of the total quantity of mineral material in coal. A distribution of such a fine mineral material throughout the organic phase leads to a significant interfacial volume and could be connected to the effects of hydrothermal pretreatment. This view is in line with suggestions by Mraw et al. 12 that mineral material within the organic phase could be significant to the behavior of coal in general.

\footnotetext{
*Pyrrhotite would be formed in the conversion step anyway. However, its formation at lower temperatures in the pretreatment step would maintain the fine dispersal and benefit the conversion.
} 
Coal Pyrolysis, Volatility, and Volatile Products. The effects of pretreatment on volatility properties were studied by FIMS, comparing the volatiles from both the as-received sal and the hydrothermally pretreated material. The samples were heated slowly in the inlet assembly from ambient to $500^{\circ} \mathrm{C}$, and the signal was recorded throughout the heating period. The results are shown in Figure 3. The total volatile yields were virtually identical, $22 \%$ and $23 \%$ of the as-received and pretreated samples, respectively; however, as shown in 3a, the FIMS volatiles from the pretreated coal evolve at somewhat lower temperatures. Figure $3 \mathrm{~b}$ shows the $\bar{M}_{n}$ of evolving material plotted against evaporation temperature. The profile for the as-received coal steadily increases to a single maximum with increasing temperature, a behavior expected from the thermolysis of a highly crosslinked material. The profile for the pretreated material, however, is clearly different. It appears to be the sum of profiles for the as-received coal and for a second, more volatile quantity of condensibles produced by the pretreatment, a view consistent with the fact that the number average molecular weight of the volatiles is reduced from 347 dalton for the tar from the as-received material to 326 dalton for the pretreated coal tar.
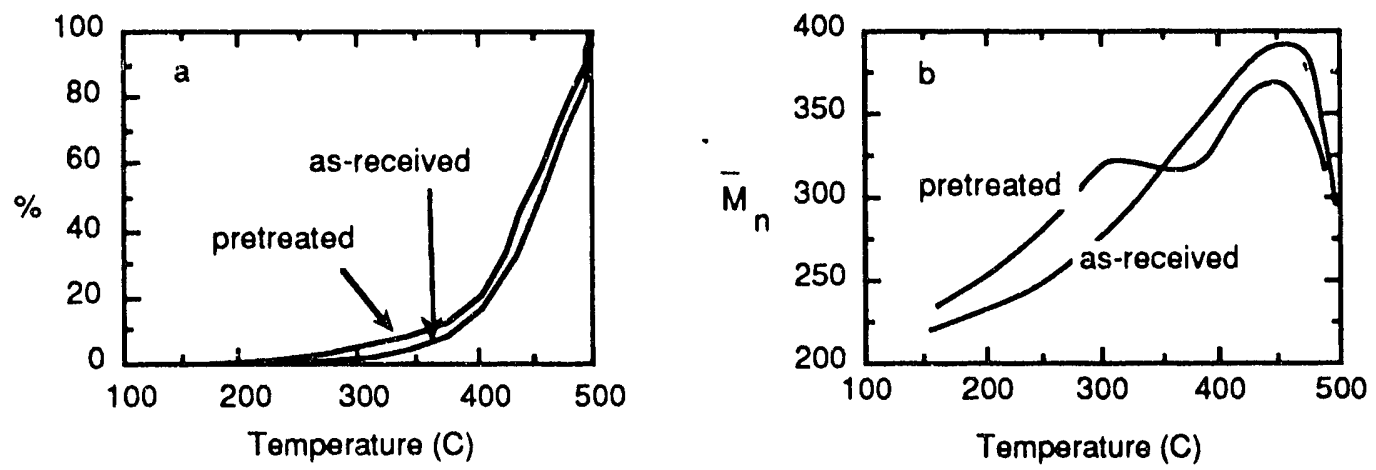

Figure 3. FIMS analysis of pretreated and as-received Illinois No. 6 coal. a) Evap-oration profiles. b) Number average molecular weights.

Additional FIMS data are shown in Figure 4, which shows the differences in the distribution of molecular weights in the pretreated and as-received samples. Specifically the figure plots the response difference [pretreated minus as-received] against molecular weight intervals up to 750 dalton. The figure demonstrates a broad enrichment in lower molecular weight material at the expense of higher weight tars. Thus the behavior is not merely a release of trapped material. Rather, the results suggest that the treatment changes the coal in some manner such that the tar precursors generate additional lower weight material. 


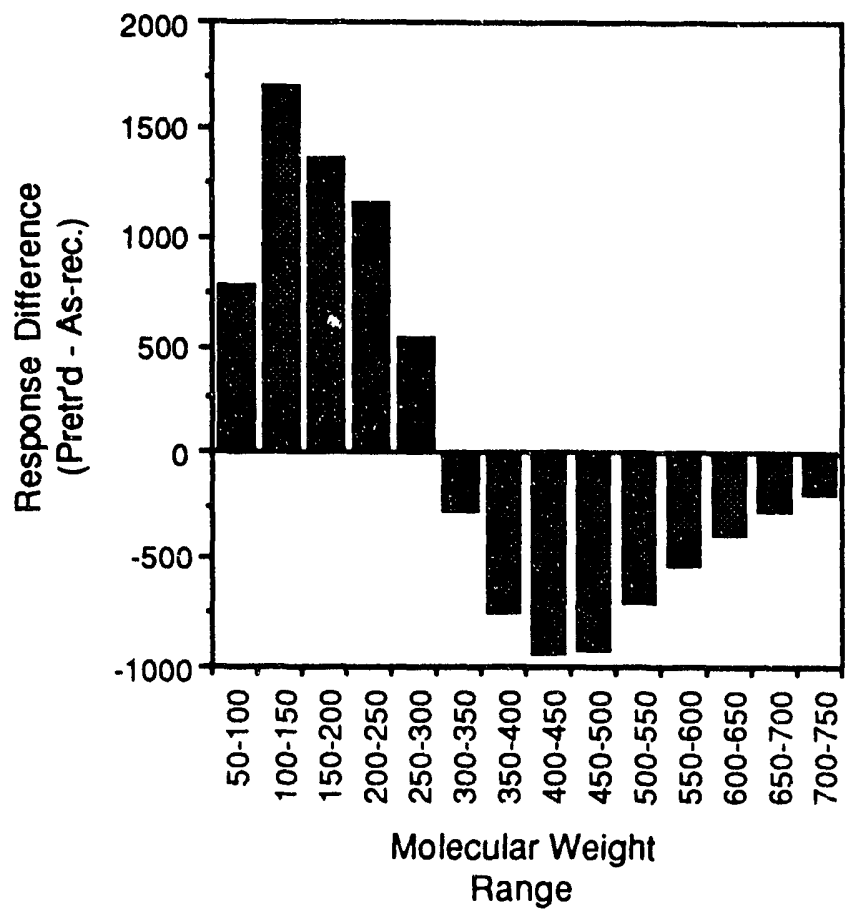

Figure 4. FIMS response differences as a function of molecular weight range.

The response data have been normalized so that the values from the two materials can be directly compared.

This absolute increase in lighter material is demonstrated by yet other FIMS data in Figure 5. The figure shows the thermal evolution for several arenes and their corresponding methyl, dimethyl, and trimethyl derivatives. ${ }^{*}$ The figure shows that they evolve distinctly differently after pretreatment, distilling from the matrix at considerably lower temperatures.

\footnotetext{
"The FIMS mass values can correspond in some cases to several different structures. However, given the relatively low molecular weights here, it is likely that the assignments are primarily as assigned. An exception is the case for the naphthalenes, which have the same molecular weights as the family of alkanes.
} 

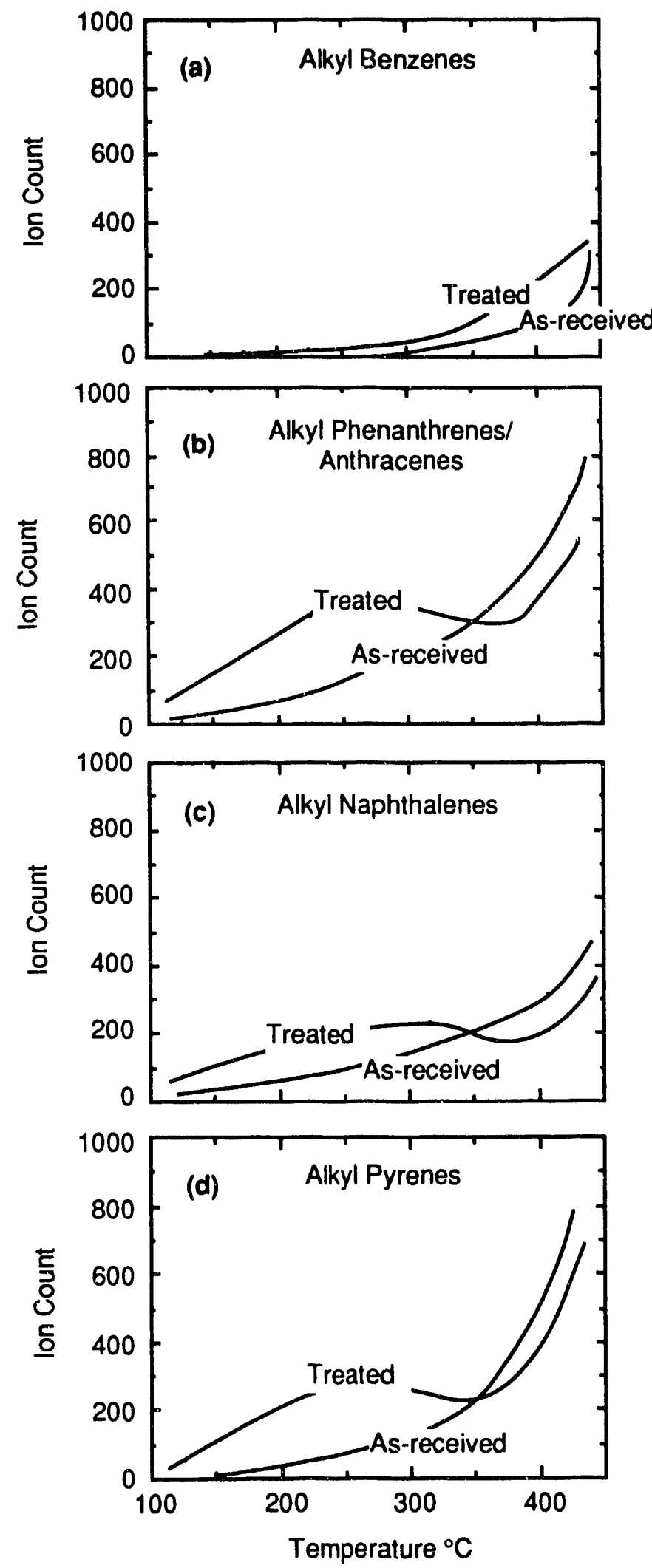

Figure 5. Thermal generation of arenes under hydrothermal conditions. 


\section{TASK 3: SYNTHESIS OF CLUSTERS AND REACTIVITY WITH MODEL SYSTEMS}

The principal goal of Task 3 was is to synthesize catalysts that are highly reactive toward hydrogenolysis reactions at moderate temperatures to cleave the weak links in the coal matrix, such as the ether cross-inks, and remove the phenolics and nitrogen-containing species that may cause regressive reactions during coal liquefaction. In past work we have found that organometallic clusters provide a much higher activity than their counterparts prepared by conventional aqueous impregnation techniques. 3,4 A portion of the synthesis and evaluation of the supported catalysts was conducted in conjunction with DOE Contract \# DE-FG22-85PC80906 and is described in Appendices $\mathrm{C}$ and $\mathrm{D}$.

Ammonium molybdenum tetrathiolate was obtained from Alfa Chemicals and cobalt chloride from Baker Chemical Co. Bis(tricarbonyl cyclopentadienylmolybdenum) was obtained from Alfa and used as received. Tetrahydrofuran (THF) was distilled from sodium benzophenone under nitrogen and stored in a nitrogen atmosphere.

The CoMo thiolate cluster was synthesized by a method similar to those of Konings et al., 13 and Muller et al. ${ }^{14,15}$ To a stirred solution of $0.422 \mathrm{~g}(1.77 \mathrm{mmol}) \mathrm{CoCl}_{2}$ in $20 \mathrm{~mL}$ of water was added $0.91 \mathrm{~g}(3.50 \mathrm{mmol})$ of $\left(\mathrm{NH}_{4}\right)_{2} \mathrm{MoS}_{4}$. The solution changed from light pink to a black colloidal suspension. The suspension was allowed to stir overnight at room temperature, and then filtered to leave a clear solution and $0.89 \mathrm{~g}$ of a black residue. Analysis: $\mathrm{Mo}, 30.93 \%$; Co, 9.77\%; S, 43.05\%; Cl, 0.38\%; N, 2.10\%.

The sulfur-containing molybdenum cluster, $\mathrm{Cp}_{2} \mathrm{Mo}_{2}(\mu-\mathrm{SH})_{2}(\mu-\mathrm{S})_{2}$, was synthesized by a modification of DuBois et al. ${ }^{16}$ Bis(tricarbonyl cyclopentadienylmolybdenum) was refluxed with an excess of sulfur for $48 \mathrm{~h}$ in dry benzene. The crude polymeric product, $\left(\mathrm{Cp}_{2} \mathrm{Mo}_{2} \mathrm{~S}_{\mathrm{x}}\right)_{\mathrm{n}}$, which is air stable, was filtered and dried under vacuum to give a purple solid. This crude solid was then transferred into a Parr bomb with $20 \mathrm{~mL}$ of tetrahydrofuran (THF) under 500 psi of hydrogen pressure and allowed to stir at room temperature for $72 \mathrm{~h}$ to yield a solution of the molybdenum sulfido dimer.

The sulfur-containing molybdenum cobalt cluster, $\mathrm{Cp}_{2} \mathrm{Mo}_{2} \mathrm{Co}_{2}\left(\mu_{3}-\mathrm{S}\right)_{2}\left(\mu_{4}-\mathrm{S}\right)(\mathrm{CO})_{4}$, was synthesized by treating $\mathrm{Co}_{2}(\mathrm{CO})_{8}$ with $\mathrm{Cp}_{2} \mathrm{Mo}_{2}(\mu-\mathrm{SH})_{2}(\mu-\mathrm{S})_{2}$, in THF solution by the method of Curtis and Williams. ${ }^{17}$ 
The molybdenum(II) acetate dimer, $\mathrm{Mo}_{2}(\mathrm{OAc})_{4}$ was synthesized by the method of Wilkinson and coworkers. ${ }^{18}$

The sulfur-containing iron cluster, $(\mu-\mathrm{S} 2) \mathrm{Fe} 2(\mathrm{CO}) 6$ was synthesized by the method of Bogan et al., 19 using iron carbonyl and sodium sulfide. 


\section{TASK 4: CATALYTIC CONVERSION OF COAL}

The purpose of this task was to interlink or combine the pretreatment with highly dispersed catalysts. If we can impregnate the coal matrix with highly active hydrogenolysis or hydrogenation catalysts and cause them to be in contact with the functional groups in the coal, perhaps we can break the weak links in the coal and remove the heteroatoms that most likely are the source of regressive reactions. The experimental methods and results are as follows:

\section{EXPERIMENTAL PROCEDURES}

Conversions in the $300-\mathrm{mL}$ stirred autoclave used $5.0 \mathrm{~g}$ of coal pretreated with approximately 0.003 moles of catalyst, $30 \mathrm{~g}$ of solvent (water, tetralin, or $\mathrm{n}$-hexadecane), and 500 psi of either hydrogen or carbon monoxide. Conversion temperatures ranged from $400-425^{\circ} \mathrm{C}$. Pretreatment of coal with ammonium thiomolybdate was conducted as follows. The thiomolybdate was disolved in $10 \mathrm{~mL}$ of water and added to the coal in a $45-\mathrm{mL}$ Parr bomb. For the aqueous mixed metal impregnations, the thiomolybdate was first added in $5 \mathrm{~mL}$ of water, and then a metal salt such as cobalt chloride in $5 \mathrm{~mL}$ of water was added in a 2:1 mole ratio of molybdenum to metal salt. The bomb was heated to $250^{\circ} \mathrm{C}$ for 30 minutes and the aqueous solution was removed as described in Task 2. For pretreatment with organometallic complexes, the coal was impregnated by adding a THF solution of the desired complex [or toluene in the case of $\mathrm{Mo}_{2}(\mathrm{OAc})_{4}$ ] directly to the coal. The solvent was then removed by evaporation under reduced pressure to leave the coal coated (or impregnated) with the desired catalyst. The methods of conversion into toluene-soluble material were described in Task 2.

For low temperature small-scale reactions, approximately $1 \mathrm{~g}$ of coal and $10 \mathrm{~mL}$ of water and catalyst were mixed in a 45 -mL Parr autoclave. Ammonium thiomolybdate $(0.20 \mathrm{~g})$ was used for the molybdenum impregnations. The autoclave was purged and pressurized with $500 \mathrm{psi}$ of hydrogen and heated at $250^{\circ} \mathrm{C}$ for $30 \mathrm{~min}$. The mixture was transferred under nitrogen, centrifuged, washed, and dried at $76^{\circ} \mathrm{C}$ under vacuum for 6 hours to remove the residual water. The dry product was then placed into the Parr autoclave with $10 \mathrm{~mL}$ of hexane and pressurized with $500 \mathrm{psi}$ of hydrogen. The autoclave was heated at $300^{\circ} \mathrm{C}$ for 4 hours to hydrogenate the coal. The hexane layer was removed, and the product was dried and extracted with THF under nitrogen using a Soxhlet extraction apparatus. The combined hexane and THF solution was concentrated 
under reduced pressure to give the THF-soluble material. The soluble material and the extracted residue were then dried for $12 \mathrm{~h}$ at $76^{\circ} \mathrm{C}$ under vacuum.

\section{RESULTS}

\section{Low Temperature Hydrogenations}

The purpose of these experiments was to determine the effects of metals impregnated into the coal matrix at low temperatures $\left(300^{\circ} \mathrm{C}\right)$. Since we were using aqueous pretreatments and aqueous conversions, we began our tests with water-soluble catalysts. Molybdenum tetrathiolate was chosen because it is an excellent hydrogenation and liquefaction catalyst precursor and can be used to form mixed metal sulfide clusters, which may be used as hydrogenolysis catalysts. ${ }^{13-15}$

Table 4 lists the THF solubilities of Illinois No. 6 coal obtained as a function of catalyst and method of impregnation. As shown in these data, the impregnation did little in terms of changes in THF solubility. For example, the solubility dropped from 10-11 wt\% with no impregnation to 7-8 wt\% with impregnation. These results are disappointing in that we had hoped that the impregnation of molybdenum, and especially with mixed metals, would aid in cleaving heteroatoms at low temperatures and thus increase the solubility. However, the results on these preliminary experiments are not surprising for the following reasons. First, our results in forming the mixed metal clusters by the method of Konings and Muller ${ }^{13-15}$ gave insoluble precipitates, thus we most likely do not have these metal clusters impregnated into the coal. Second, as described in Task 3, these clusters were not as active as expected for hydrogenolysis reactions, requiring $350^{\circ} \mathrm{C}$ to catalyze $\mathrm{HDO}$ reactions. Third, $300^{\circ} \mathrm{C}$ may be too high a hydrogenating temperature, since as shown from work by Shabtai and Skulthai, ${ }^{20}$ mild hydrotreatment of coal at temperatures of $275^{\circ} \mathrm{C}$ gave the maximum THF solubilities. At higher temperatures such as $290^{\circ} \mathrm{C}$, the THF solubilities decreased over that of the nonimpregnated coal.

For comparison, we used an organometallic sulfido complex, $\mathrm{Cp}_{2} \mathrm{Mo}_{2}(\mu-\mathrm{SH})_{2}(\mu-\mathrm{S})_{2}$. We felt that this complex was an excellent choice as a precursor since it is an easily prepared, oilsoluble, sulfided molybdenum catalyst and is similar in stoichiometry to the $\mathrm{MoS}_{2}$, which is considered the active liquefaction catalyst.

The impregnations with the organometallic complexes and subsequent hydrogenations gave improved THF yields for both the Mo and CoMo complexes, increasing from $\approx 8 \%-11 \%$ for the aqueous pretreatments to $16 \%-17 \%$ for the organometallic pretreatments. The effect of these 
Table 4

THF SOLUBILITY OF IMPREGNATED COALa

\begin{tabular}{|c|c|c|c|}
\hline Pretreatment & MO\% & $x \% b$ & THF Sol. (wt\%) \\
\hline None & 0 & 0 & 10.2 \\
\hline$A q^{c}$ & 0 & 0 & 9.4 \\
\hline $\mathrm{MoS}_{4}(\mathrm{aq})$ & 6.5 & 0 & 7.5 \\
\hline $\mathrm{Aq} / \mathrm{MoS}_{4}(\mathrm{aq})$ & 5.0 & 0 & 11.4 \\
\hline $\mathrm{MoS}_{2}(\mathrm{OM})$ & 4.0 & 0 & 16.3 \\
\hline CoMo(aq) & 5.6 & 1.6 & 7.4 \\
\hline CoMo(OM) & $\ldots d$ & $\ldots d$ & 17.0 \\
\hline
\end{tabular}

$\mathrm{a}_{\mathrm{Coal}}(1.0 \mathrm{~g})$ was impregnated with molybdenum thiomolybdate $(0.20 \mathrm{~g}, 0.77 \mathrm{mmol})$ in $10 \mathrm{~mL}$ of water at $250^{\circ} \mathrm{C}$ for 30 minutes. For the mixed metals, $0.385 \mathrm{mmol}$ of metal salt was added.

bx refers to the second metal.

CNo metal was impregnated into the coal.

dAnalysis not determined. 
complexes at higher temperatures may be substantial. In the following section, we describe our results for conversions at $400^{\circ} \mathrm{C}$ and $425^{\circ} \mathrm{C}$.

\section{Aqueous conversions with $\mathrm{CO} / \mathrm{H}_{2} \mathrm{O}$}

To compare catalytic conversions with the $\mathrm{KOH}$-catalyzed $\mathrm{CO} /$ water conversions, we conducted experiments substituting molybdenum for the $0.1 \mathrm{M} \mathrm{KOH}$ solution. The catalysts were either ammonium molybdate, $0.742 \mathrm{~g}(0.14 \mathrm{M}$ solution), or ammonium thiomolybdate, $0.781 \mathrm{~g}$ ( $0.10 \mathrm{M}$ solution). Normally, we would expect high-valent Mo species to be poor catalysts for the water-gas-shift (WGS) conversions, especially in nonbasic media; however, both Mo catalysts were active, and the thiolate catalyst was far more active.

The conversion of the coal to toluene-soluble material parallels the WGS activity, with the $\mathrm{NH}_{4} \mathrm{MoS}_{4}$ catalyst producing solubilities in the range of $60 \%$, compared with $30 \%$ for the $\mathrm{NH}_{4} \mathrm{MoO}_{4}$ catalyst, as shown in Table 5. Pretreatment of the coal allows a much greater WGS reaction when $\mathrm{KOH}$ is the catalyst. In contrast, pretreatment with either Mo catalyst gave no change in WGS reactivity. One possible explanation for this difference from $\mathrm{KOH}$-catalyst reactions is that the aqueous pretreatment may remove or disrupt the coal matrix, which is detrimental to the $\mathrm{KOH}$-catalyzed reaction. We found evidence for this possibility in earlier work in which we tried to convert coal using $\mathrm{KOH}$ in a quartz liner and found almost negligible conversion and a badly etched quartz reactor.

\section{Nonaqueous Conversions}

The data comparing the yields of toluene-soluble material and elemental analyses of these fractions are listed in Table 6. The toluene-soluble (TS) yield is derived from the weight of the toluene insoluble material corrected for ash. Runs 1 and 2 are the average of typical conversions using no catalyst and are the baseline runs. Run 2 was similar to run 1, except that water was added to simulate the residual water in runs where molybdenum was impregnated in an aqueous solution. The aqueous runs 6 through 9 gave conversions very similar to those without catalyst. We rationalized these results by suggesting that the high ratio of tetralin to coal (6 to 1$)$ and low concentration of catalyst would minimize any differences in activity. In run 5, where the coal was dried after an aqueous impregnation, the conversion dropped to $41 \%$. Interestingly, the $\mathrm{Al}_{2} \mathrm{O}_{3}$ supported catalyst in run 14 also had the same level of conversion and may be caused by regressive reactions catalyzed by the support. 
Table 5

GAS ANALYSES FOR WGS CONVERSIONS

\begin{tabular}{|c|c|c|c|c|}
\hline Pretreatment & $\begin{array}{c}\text { TS } \\
\text { Yield }\end{array}$ & $\begin{array}{c}\text { co } \\
\text { Converted } \\
\text { (mmol) } \\
\end{array}$ & $\begin{array}{c}\mathrm{H}_{2} \\
\text { Found } \\
\text { (mmol) }\end{array}$ & $\begin{array}{c}\mathrm{H}_{2} \\
\text { Consumed } \\
\text { (mmol) } \\
\end{array}$ \\
\hline $\begin{array}{l}\text { None } \\
\text { None }\end{array}$ & $\begin{array}{l}35.6 \\
35.4\end{array}$ & $\begin{array}{l}117 \\
104\end{array}$ & $\begin{array}{l}48 \\
32\end{array}$ & $\begin{array}{l}68 \\
72\end{array}$ \\
\hline $\begin{array}{l}3 \mathrm{M} \mathrm{NH}_{3} \\
3 \mathrm{M} \mathrm{NH}_{3}\end{array}$ & $\begin{array}{l}48.9 \\
46.6\end{array}$ & $\begin{array}{l}235 \\
253\end{array}$ & $\begin{array}{l}172 \\
228\end{array}$ & $\begin{array}{l}63 \\
25\end{array}$ \\
\hline $\begin{array}{l}\mathrm{H}_{2} \mathrm{O} \\
\mathrm{H}_{2} \mathrm{O}\end{array}$ & $\begin{array}{l}69 \\
73.4\end{array}$ & $\begin{array}{l}271 \\
308\end{array}$ & $\begin{array}{l}194 \\
261\end{array}$ & $\begin{array}{l}77 \\
47\end{array}$ \\
\hline $\mathrm{H}_{2} \mathrm{O} / \mathrm{O}_{2}$ & 51.3 & 259 & 187 & 72 \\
\hline $\mathrm{NH}_{4} \mathrm{MoO}_{4} /$ none & 39.3 & 157 & 79 & 78 \\
\hline $\mathrm{NH}_{4} / \mathrm{H}_{2} \mathrm{O}$ & 47.3 & 157 & 74 & 83 \\
\hline $\mathrm{MoO}_{4} / \mathrm{H}_{2} \mathrm{O}$ & 31.2 & 143 & 51 & 92 \\
\hline $\mathrm{MoS}_{4}$-none & 71.0 & 340 & 255 & 85 \\
\hline $\mathrm{MoS}_{4}$-none & 55.9 & 332 & 190 & 142 \\
\hline $\mathrm{MoS}_{4}-\mathrm{H}_{2} \mathrm{O}$ & 56.3 & 343 & 246 & 97 \\
\hline $\mathrm{MoS}_{4}-\mathrm{H}_{2} \mathrm{O}$ & 62 & 345 & 213 & 132 \\
\hline
\end{tabular}


Runs 10 and 11 were conducted to compare the dispersed soluble molybdenum tetracetate and molybdenum thiolate catalysts. Both are organometallic clusters, with the tetracetate containing a molybdenum -oxygen bond, whereas the thiolate contains a molybdenum-sulfur bond. As shown for these conversions, the molybdenum tetraacetate gave a increase in TS fraction (56\%) compared with the best runs for the aqueous pretreatment (runs 6-9), with conversions of 51\%$54 \%$ TS. In contrast, the molybdenum sulfido complex gave an increase of TS to $61 \%$, and the mixed metal sulfido cluster (run 13) gave a conversion of $67 \%$ into toluene-soluble material, which is the highest conversion at $400^{\circ} \mathrm{C}$, compared with the aqueous impregnated CoMo cluster of $58 \%$ (run 12). The differences between the catalysts were even greater when the liquefaction experiments were done at $425^{\circ} \mathrm{C}$. As shown in run 19 , the convertibility increased to $84 \%$ TS for the $\mathrm{Mo}(\mathrm{OM})$ catalyst, compared with only $69 \%$ for the noncatalyzed conversion (run 18 ) and $76 \%$ (run 20) for the coal impregnated with aqueous Mo.

Iron catalysts are effective catalysts, although not nearly as effective as the molybdenum catalysts, and are thought to work in a different manner. For instance, the molybdenum catalysts are good hydrogenation catalysts, whereas the iron catalysts appear to function by removing oxygen functionalities. For these reactions, $\mathrm{Fe}(\mathrm{CO})_{5}$ was compared with the iron sulfido dimer $\left(\mu-S_{2}\right) \mathrm{Fe}_{2}(\mathrm{CO})_{6}$, designated as $\mathrm{Fe}_{2} \mathrm{~S}_{2}$ in Table 6 . These catalysts were used at the same amounts ( 0.003 mole) as used for the molybdenum catalysts, so lower conversions were expected. Thus, in tetralin, both catalysts gave similar conversions as the baseline case, with the $\mathrm{Fe}(\mathrm{CO})_{5}$ catalyst giving $47 \%$ conversion (runs 15 and 16 ) and the $\mathrm{Fe}_{2} \mathrm{~S}_{2}$ catalyst $49 \%$ conversion (run 17). Interestingly, the TS product of the $\mathrm{Fe}_{2} \mathrm{~S}_{2}$ catalyst was a tar, whereas the products from the $\mathrm{Fe}(\mathrm{CO})_{5}$-catalyzed reaction, the molybdenum-catalyzed reactions, and the baseline reactions were brittle solids.

To expand on the differences between these to iron catalysts, we also ran the conversions in a nonreactive solvent, $\mathrm{n}$-hexadecane (runs 22 and 23). The advantage of conversions in this solvent is that we can distinguish between the effects of the solvent and the catalyst, since tetralin easily allows high conversions because of its $\mathrm{H}$-donating capacity and ability to mediate radical hydrogen transfer reactions. In fact, the inability of the catalysts to significantly increase conversions in tetralin may actually be because of competitive reactions with tetralin. Thus reactions using the inert solvent will eliminate these possible competing reactions and will be much like pyrolysis reactions. The conversions in hexadecane using $\mathrm{Fe}_{2} \mathrm{~S}_{2}$ (run 23) are slightly higher (29\%) than those with $\mathrm{Fe}(\mathrm{CO})_{5}$ in run $22(24 \%)$ and the baseline case of $25 \%$ (run 21 ). However, these conversions are still similar, and we hope to be able to repeat these reactions on lower rank 
coals with larger amounts of catalyst and at higher temperatures, under conditions where other workers have found İarger influences of iron based catalysts.

Runs 24 and 25 show the effect of the $\mathrm{Mo}(\mathrm{aq})$ and $\mathrm{Mo}(\mathrm{OM})$ dispersed catalysts in hexadecane. As shown in these runs, the Mo(aq) increases the conversion from $25 \%$ to $41 \%$, while the $\mathrm{Mo}(\mathrm{OM})$ catalyzed conversion gives $54 \%$ yield. This high conversion in hexadecane is significant, in that it is approximately the same as in tetralin, suggesting that if, the catalyst is well enough dispersed and active, good conversion solvents are not necessary.

From the elemental analyses shown in Table 6, we see that all the catalyzed reactions give TS products with a lower oxygen content than the noncatalyzed runs. For instance, the molybdenum catalyzed reactions have the lowest oxygen content of $4.6 \%$ to $4.8 \%$ oxygen, the iron-catalyzed reactions give a 5\% oxygen content, and the baseline runs have an oxygen content of $6 \%-6.5 \%$. The mixed metal organometallic CoMo catalyst produced the lowest oxygen content of $4.4 \%$, consistent with the high HDO activity of CoMo catalysts. The nitrogen content does not seem to be much changed, with the molybdenum-catalyzed conversions actually showing a slightly higher nitrogen content. The lower nxygen content is one of the goals of our work, since much of the retrogressive reactions are thought to center through this group. However, the type of oxygen functionality has not been determined during this study.

The nature of the coal impregriated with the catalysts was also examined through use of X-ray diffraction methods. Attempts were made by SEM to determine the dispersion of the molybdenum catalyst by looking both at the starting impregnated coal and the residue of the coal after conversion. However because of the low concentration of molybdenum and the overlap of the X-ray diffraction pattern of molybdenum and sulfur, the dispersion of molybdenum could not be distinguished from the background sulfur. However, we did see a highly dispersed spectrum and no islands of molybdenum (or sulfur), which would indicate that our methods orevented segregation of the catalyst during the dispersion or during the catalytic conversions

Another observation was that the molybdenum in the coal impregnated by aqueous techniques was notably associated with oxygen, presumably as the metal oxide, whereas the molybdenum formed from the organometallic method was not and was associated only with sulfur. Thus the organometallic method apparently formed the final product, which was in the fully sulfided state (the more active state).

The X-ray diffraction pattern of toth residues was very weak and could not be identified, other than they appeared to be similar to a metal sulfide pattern. The X-ray diffraction patterns of the iron complexes were quite similar, showing in both cases, the pattern of pyrrhotite. Thus to form this product, iron carbonyl must extract the sulfur from the coal, whereas the sulfido dimer is 
already in the correct stoichiometry for the product. As with the molybdenum complex, we believe that having the catalyst in the active state as early as possible during the conversion process will improve the yields and quality of product. We hope to be able to better understand such effects in future work. 
Table 6

CATALYZED TETRALIN CONVERSIONSa

\begin{tabular}{|c|c|c|c|c|c|c|c|}
\hline Run & Pretreatment & $\begin{array}{l}\% \text { TS } \\
\text { (daf) }\end{array}$ & $\% \mathrm{C}$ & $\% \mathbf{H}$ & $\% \mathbf{N}$ & $\mathrm{H} / \mathrm{C}$ & $\% 0$ \\
\hline 1 & None & $48^{b}$ & 84.8 & 7.1 & 1.13 & 1.0 & 6.0 \\
\hline 3 & $4 \mathrm{~mL} \mathrm{H}_{2} \mathrm{O}^{\circ}$ & $49^{b}$ & 84.4 & 7.1 & 0.94 & 1.0 & 6.5 \\
\hline 5 & $\operatorname{MoS}_{4} /$ dried & 41 & 84.6 & 7.1 & 1.45 & 1.0 & 4.6 \\
\hline 6 & $\mathrm{MoS}_{4} / 4 \mathrm{~mL}$ & 51 & - & - & - & - & - \\
\hline 7 & $\mathrm{MoS}_{4} / 4 \mathrm{~mL}$ & 54 & - & - & - & - & - \\
\hline 8 & $\mathrm{MoS}_{4} / \mathrm{Wet}$ & 53 & 85.2 & 7.1 & 1.50 & 1.0 & 4.8 \\
\hline 9 & $\mathrm{MoS}_{4} / \mathrm{Wet}$ & 52 & - & - & - & - & - \\
\hline 10 & $\operatorname{MoS}(O M)^{d}$ & 61 & 86.8 & 7.45 & 1.49 & 1.0 & 4.6 \\
\hline 11 & $\mathrm{Mo}_{2}(\mathrm{OAC})_{4}(\mathrm{OM})^{\mathrm{d}}$ & 56 & - & - & - & - & - \\
\hline 12 & $\mathrm{CoMo}(\mathrm{Aq})$ & 58 & - & - & - & - & - \\
\hline 13 & CoMos $(O M)^{d}$ & 67 & 85.8 & 7.70 & 1.23 & 1.1 & 4.4 \\
\hline 14 & $\mathrm{Mo} / \mathrm{Al}_{2} \mathrm{O}_{3}$ & 41 & - & - & - & - & - \\
\hline 15 & $\mathrm{Fe}(\mathrm{CO}) 5$ & 47 & - & - & - & - & - \\
\hline 16 & $\mathrm{Fe}(\mathrm{CO})_{5}$ & 47 & 85.9 & 7.28 & 0.92 & 1.0 & 5.0 \\
\hline 17 & $\mathrm{Fe}_{2} \mathrm{~S}_{2}$ & 49 & 86.2 & 7.32 & 1.07 & 1.0 & 5.1 \\
\hline 18 & None $425^{\circ} \mathrm{Ce}$ & 69 & - & - & - & - & - \\
\hline 19 & $\operatorname{MoS}(O M)^{d} 425^{\circ} C^{e}$ & 84 & - & - & - & - & - \\
\hline 20 & $\mathrm{MoS}_{4} / 4 \mathrm{~mL} 425^{\circ} \mathrm{C}^{\mathrm{e}}$ & 76 & - & - & - & - & - \\
\hline 21 & None & $25^{f}$ & - & - & - & - & - \\
\hline 22 & $\mathrm{Fe}(\mathrm{CO}) 5$ & $24^{f}$ & - & - & - & - & - \\
\hline 23 & $\mathrm{Fe}_{2} \mathrm{~S}_{2}$ & $29^{f}$ & - & - & - & - & - \\
\hline 24 & Mo(aq) & $41^{f}$ & - & - & - & - & - \\
\hline 25 & $\operatorname{MoS}(O M)$ & $54^{f}$ & - & - & - & - & - \\
\hline
\end{tabular}

a Reaction conducted in $300-\mathrm{mL}$ autoclave of $5 \mathrm{~g}$ coal in $30 \mathrm{~g}$ of tetralin and $500 \mathrm{psi} \mathrm{H}_{2}$ at $400^{\circ} \mathrm{C} / 20 \mathrm{~min}$. bCoal $(5 \mathrm{~g})$ was pretreated with $10 \mathrm{~mL} \mathrm{H} \mathrm{H}_{2}$ at $250^{\circ} \mathrm{C}$ for $30 \mathrm{~min}$ and 500 psi $\mathrm{N}_{2}$ in a $45-\mathrm{mL}$ Parr reactor.

CWater $(4 \mathrm{~mL})$ added to the tetralin.

dOM refers to organometallic precursor.

e Conversion run at $425^{\circ} \mathrm{C}$.

'Conversion run in $\mathrm{n}$-hexadecane. 


\section{DISCUSSION}

The results from Task 2 suggest that coal contains regions with structural components significantly reactive under the hydrothermal environment. Although the specific mechanism for this process remains to be developed, this activity is reminiscent of findings in studies of accelerated maturation of oil shale, where hydrothermal treatment (hydrous pyrolysis) leads to the production of petroleum hydrocarbons. ${ }^{21}$ Recent results by Hoering 22 are particularly applicable to the present case. In that work, the treatment of preextracted Messel shale with water at $330^{\circ} \mathrm{C} / 3$ days generated petroleum hydrocarbons including long chain normal alkanes, aromatics, and biomarkers when heated in liquid water at $330^{\circ} \mathrm{C} / 3$ days. When $\mathrm{D}_{2} \mathrm{O}$ was used, deuterium was heavily incorporated into the hydrocarbons.

Hoering's control results and the distributions of isotopic isomers rule out virtually all sources for the hydrocarbons and exchange except chemistry at the preexisting interphase layer at the mineral/kerogen boundary. ${ }^{*}$ Both the fact that the shale was preextracted and the control results emphasize the point that the hydrocarbons were not merely freed, but rather generated in some manner by the water. Thus the mineral component of the oil shale, or more specifically the interfacial volume joining the kerogen and mineral phases, must play a significant role in the process.

In line with what has been seen in the oil shale work, the pretreatment-generated hydrocarbons and phenols for coal appear to represent a further or more complete maturation of some fraction of the organic material within the coal. These observations could have an impact in two areas. The first is in the area of coal structure, where immature, reactive regions have not been included in the structures considered at present. Indeed, the broad distribution of the ultrafine mineral component in coal within the organic phase should provide a large interfacial volume within the organic phase, serving as a substantial, unrecognized region of reactivity within the strusture.

\footnotetext{
*Unextracted alkanes or alkenes as sources were climinated in controls with extracted shale spiked with an $\mathrm{n}$-alkane or terminal $\mathrm{n}$-alkene. The alkane was recovered unexchanged, and $60 \%$ of the olefin was recovered as the corre ponding alkane and only slightly tagged. Thermally generated radicals from the kerogen could also be dismissed. Organic radicals at these conditions should react only very slowly with $\mathrm{D}_{2} \mathrm{O}$ on thermochemical grounds. Any resulting deuterated hydrocarbons would have an isotope distribution far too narrow to match the observed, broad distributions at any rate. It can be shown that a multiple, sequential introduction of deuterium into the alkanes through a free radical chain would yield a considerably narrower distribution of isotope isomers.
} 
The second area of interest is the more practical one of conversions to coal liquids and pyrolytic tars. It seems clear that the hydrothermal pretreatment changes the coal in some manner that favorabiy affects the product quality substantially and, as in the $\mathrm{CO} /$ water liquefaction case, favorably affects the yields. The conversions of coals of lower rank, i.e., less mature coals, could particularly benefit in terms of both product quality and product quantity.

The second portion (Tasks 3 and 4) of this project also shows important benefits to coal conversion technology. It deals with synthesizing catalysts designed to cleave the weak links in the coal structure and then linking these catalysts with the pretreatment methods in Task 2 . The results show that highly dispersed catalysts can effectively be used to increase the yields of soluble material. An important aspect of highly dispersed catalysts are that they can effectively catalyze coal conversion even in poor liquefaction solvents, thus making them very attractive in processes such as coprocessing where inexpensive liquefaction media such as resids are used.

The types of catalysts used were both metal salts that are soluble in water, such as ammonium molybdenum tetrathiolate, and metal complexes that are soluble in organic media. The organometallic catalysts were found to be far more reactive, and we suggest the following possible reasons for the high reactivities. The first reason is that the organometallic complexes are most likely more highly dispersed and have smaller particle sizes than the aqueous precursors. Recently, Thompson and Carvill estimated the particle sizes of $\mathrm{MoS}_{2}$ formed from the molybdenum thiolate precursor to be less than $15 \AA .23$ In contrast, estimates of particles sizes from aqueous impregnation techniques have been in the 100 's of angstroms. ${ }^{24}$ Thus the effective surface area must be far greater for the organometallic precursors.

The second possible reason for the increase in reactivity is that these complexes are already in the correct stoichiometry of the $\mathrm{MoS}_{2}$ catalyst and are already active for hydrogenation and hydrogenolysis reactions. The aqueous precursor, in contrast, requires high temperature activation to form the $\mathrm{MoS}_{2}$ catalyst ${ }^{25}$ and thus will not be effective during the early stages of conversion.

The fact that the effect of catalysts was greater in the hexadecane solvent than in the tetralin solvent is intriguing and suggests that competitive reactions must be occurring in the tetralin. The high extent of conversion in hexadecane, which is essentially a nonreactive solvent, shows that a highly dispersed catalyst can be very effective without expensive recycle solvents. 


\section{REFERENCES}

1. M. B. Neuworth and E. C. Moroni, Fuel Processing Technology 8, 231-239 (1984).

2. (a) P. R. Beinkowski, R. Narayan, R. A. Greenkorn, and K-C Chao, Ind. Eng. Chem. Res., 26, 202-205 (1987).

(b) S. D. Brandes and R. A. Graff, Am. Chem. Soc. Div. of Fuel Chemistry Preprints, 32, 385-393 (1987).

(c) R. A. Graff and S. D. Brandes, Energy and Fuels, 1, 84-88 (1987).

(d) M. R. Kahn, W-Y. Chen and E. Suuberg, Energy and Fuels, 3, 223-230 (1989).

3. A. S. Hirschon, R. B. Wilson Jr., and R. M. Laine, Am. Chem. Soc. Div. Fuel Chem. Prepr., 31(1), 310-317 (1986).

4. A. S. Hirschon, R. B. Wilson Jr., and R. M. Laine, Amer. Chem. Soc. Div. Petr. Prepr., 32(2), 268-270 (1987).

5. A. S. Hirschon, R. B. Wilson Jr., and R. M. Laine, Appl. Cat ., 34, 311-316 (1987).

6. D. S. Ross, R. M. Laine, T. K. Green, A. S. Hirschon, and G. P. Hum, Fuel, 64, 13231325 (1985).

7. T. G. Rozgonyi, M. S. Mohan, R. A. Zingaro, and J. H. Zoeller, Jr., Proceedings of the Second International Conference on Processing and Utilization of High Sulfur Coals, September 28-October 1, 1987, Carbondale, IL.

8. P. Montano in Interlaboratory Comparison of Mineral Constituents in a Sample from the Herrin (No. 6) Coal Bed from Illinois, R. Finkelman, F. L. Fiene, R. N. Miller, and F. O. Simon, Eds., U.S. Geological Survey Circular 932 (Department of the Interior, 1984).

9. (a) E. C. Thornton and W. E. Seyfried, Jr., Geochem. Cosmochim. Acta, 51, 1997-2010 (1987).

(b) W. Seyfried, Jr., personal corresponsence.

(c) P. A. Montano and V. I. Stenberg, Proceedings of the 1985 International Conference on Coal Science (The International Energy Agency, 1985), pp. 788-791.

10. R. B. Finkleman, Scanning Microscopy, 2 (1), 97-105 (1988).

11. R. M. Allen and J. B. VanderSande, Fuel, 63, 24-29 (1984).

12. S. C. Mraw, J. P. DeNeufville, H. Freund, Z. Baset, M. L. Gorbaty, and F. J. Wright, in Coal Science, Vol. 2, J. Larsen, M. L Gorbaty, and I. Wender, Eds. (Academic Press, New York, 1983), pp. 1-26. 
13. A.J.A. Konings, A. Valster, V.H.J. de Beer, and R. Prins, J. Catal., 76, 466-472 (1982).

14. A. Muller, E. Diemann, and H.-H. Heinsen, Chem. Ber., 62, 975-980 (1971).

15. A. Muller, E. Ahlborn, and H.-H. Heinsen, Z. Anorg. Allg. Chem., 386, 102-106 (1971).

16. B. A. Cowens, R. C. Haltiwanger, and M. R. DuBois, Organometallics, 6, 995-1004 (1987).

17. M. D. Curtis and P. D. Williams, Inorganic Chem., 22, 2261-2 (1983).

18. T. A. Stephenson, E. Bannister, and G. Wilkinson, J. Chem. Soc. (1964), 2538.

19. L. E. Bogan, Jr., D. A. Lesch, and T. B. Rauchfuss, J. Organometallic Chem., 250, 429438(1983).

20. J. Shabtai and T. Skulthai, 1987 International Conference on Coal Science, J. A. Moulijn et al., Eds. (Elsevier Science Publishers B. V , Amsterdam, Netherlands, 1987), pp. 761-764.

21. T. I. Eglinton, S. J. Rowland, C. D. Curtis, and A. G. Douglas, Org. Geochemistry, 10, 1041-1052 (1986).

22. T. C. Hoering, Organic Geochemistry, 5, 267-278 (1984).

23. L. T. Thompson and B. T. Carvill, American Chemical Society 198th National Meeting, Miami Beach, Florida, September 10-15, 1989.

24. W. M. Keely, P. Jerus, E. K. Dienes, and A. L. Hausberger, Catal. Rev.-Sci Eng., 26, 485-502 (1984).

25. D. Huntley, T. Parham, R. Merrill, and M. Sienko, Inorg. Chem., 22, 4144-4146 (1983). 
